\title{
A tarefa da transvaloração: esclarecimentos a partir da correspondência de Nietzsche em 1888
}

\author{
The task of transvaluation: elucidations from the \\ Nietzsche's Epistolary in 1888
}

\section{Luís Rubira \\ Universidade Federal de Pelotas}

\section{RESUMO}

Partindo para Sils-Maria em 6 de junho de I888, Nietzsche somente encontra forças para retomar plenamente sua atividade intelectual no final do verão no qual sua saúde "'foi por água abaixo' ['ins Wasser gefallen']" (Carta a Meta von Salis, 22 de agosto de I888, KsB 8.397). Após concluir o Crepúsculo dos Ídolos entre o final de agosto e o início de setembro, ele então toma coragem para empreender a "tremenda tarefa da transvaloração [Aufgabe der Umwerthung]”, esboça o projeto dessa tarefa em quatro livros e redige no dia 3 de setembro o prefácio de $O$ Anticristo. Movimentos vertiginosos que implicam numa mudança de rumo em sua filosofia, embora possam ser percebidos em sequência lógica e cronológica tanto em suas anotações de setembro quanto mais tarde em Ecce Homo, eles apenas ganham clareza no epistolário nietzschiano. Com base nele, buscaremos mostrar que embora restem dúvidas sobre o motivo que conduz o filósofo a partir de 20 de novembro a considerar $O$ Anticristo como a obra da transvaloração (abandonando a redação dos demais livros do projeto inicial), a tarefa da transvaloração - iniciada nas proximidades do lago de Silvaplana - é indissociável do pensamento do eterno retorno do mesmo.

\section{PALAVRAS-CHAVE}

Nietzsche; Transvaloração; Tarefa; Projeto; Correspondência.

\begin{abstract}
Leaving for Sils-Maria in 6 June I888, Nietzsche finds forces to completely resume his intellectual activity only at the end of the summer in which his health "had gone downhill" [ins Wasser gefallen']" (Letter to Meta von Salis, 22 August I888, кSB 8.397). After concluding the writing of Twilight of the Idols between the end of August and the beginning of September, he then dares to endeavor the "tremendous task of transvaluation [Aufgabe der Umwerthung]", he outlines the project of this task in four books and he writes, on 3 September, the preface to The Antichrist. Vertiginous movements implying a change of path in his philosophy, although they may be perceived in a logical and chronological sequence both in his annotations of September and later in Ecce Homo, they only gain clarity in the Nietzschian epistolary. Based on it, we will show that, even though there are doubts about the motive that led the philosopher, from 20 November on, to consider The Antichrist as the work of transvaluation (abandoning the writing of the other books of the initial project), the task of transvaluation - initiated in the surroundings of the Silvaplana lake - is inseparable from the thought of the eternal return of the same.
\end{abstract}

\section{KEY WORDS}

Nietzsche; Transvaluation; Task; Project; Correspondence. 
Quando o inverno atinge novamente a Europa no final do ano de I887, Nietzsche encontra-se em Nice, instalado desde o dia 22 de outubro na Pensão de Gênova, localizada na pequena rua de Saint-Etienne. A cidade francesa à beira do mediterrâneo é para ele, já há alguns anos, tal como havia dito em uma carta enviada para Malwida von Meysenburg, "o primeiro lugar favorável, de modo extraordinário" à sua saúde, haja visto que ele necessita de "um céu sereno, com sol e sem a menor nuvem" e Nice "tem em média duzentos e dez dias" por ano de um clima semelhante, algo que lhe permite ter a certeza de que "sob um céu assim, poderei levar adiante a obra da minha vida, a mais dura e cheia de renúncias que pode ter pesado sobre qualquer mortal".

Recolhido no inverno de 1887 em Nice em decorrência de "uma tarefa [eine Aufgabe] que não me permite pensar muito em mim (uma tarefa, um destino [ein Schicksal], que nomeiem como queiram) "', Nietzsche ali busca dedicar-se à elaboração da obra que, meses antes, havia anunciado ao final da Genealogia da Moral, ou seja, "A vontade de potência. Tentativa de uma transvaloração de todos os valores". ${ }^{3}$ Todavia, embora em novembro o filósofo dissesse em carta a Overbeck que em Nice ele dispunha de um "clima estimulante [...] abundância de luz [...] e um autêntico quarto de trabalho", condiçôes que lhe permitiriam levar a termo "esta tarefa que me deixou enfermo, mas que também voltará a me deixar sadio", no final de dezembro ele acaba por enviar uma missiva bem menos extensa ao amigo, na qual confessa: "o peso [die Schwere] de minha existência pesa [lastet] novamente sobre mim com mais força; quase não tive nenhum dia totalmente bom; e muita inquietação e melancolia [Schwermuth]".'

Em que pese o seu estado de ânimo, Nietzsche adentra o novo ano trabalhando continuamente na elaboração de um primeiro esboço dos temas centrais da obra que lhe cabe como "tarefa", que lhe constitui como "destino". É após mais de três meses de isolamento, de "deserto" (no sentido em que ele entende o "deserto" na seção oito da terceira dissertação da Genealogia da Moral), que em I2 de fevereiro de I888 ele elucida numa carta enviada ao Barão de Seydlitz, que está no Cairo:

Não foi nenhum "silêncio orgulhoso" o que entretanto me calou quase ante qualquer um, mas antes um silêncio muito humilde, o de um sofredor que se envergonha de denunciar o muito que sofre. Um animal se esconde em sua caverna quando está enfermo; assim, o faz também la bête philosophe [o animal filósofo]. Raramente uma voz

I Carta a Malwida von Meysenburg de fim de março de I884, кSB 6.489.

2 Carta a Franz Overbeck de I2 de novembro de I887, кsв 8.I96.

3 Genealogia da Moral, "Terceira dissertação", \$27, KSB 5.409.

Carta a Franz Overbeck de I2 de novembro de I887, кSB 8.196.

5 Cartão Postal a Franz Overbeck de 28 de dezembro de 1887, KSB 8.216. 
amistosa chega até mim. Agora estou sozinho, absurdamente sozinho; e em minha luta implacável e subterrânea contra tudo o que os seres humanos têm venerado e amado até agora (— minha fórmula para isso é "Transvaloração de todos os valores"), uma parte de mim mesmo, de maneira inadvertida, se converteu em algo assim como uma caverna algo oculto que já não se encontra, ainda que se tente buscá-lo. Mas não se vai a buscá-lo... Dito entre nós, em trio - não é impossível [es ist nicht unmöglich] que eu seja o primeiro filósofo da época, e inclusive um pouco mais, algo de decisivo e fatal, que se encontra entre dois milênios. ${ }^{6}$

Para bem entender o sentido desta declaração na carta ao Barão de Seydlitz, é importante primeiramente lembrar que, dois dias antes, Nietzsche havia escrito a Carl Spitteler argumentando (pela primeira vez) que sua obra Assim falava Zaratustra significava "o acontecimento mais profundo e mais decisivo - para a alma [...] entre dois milênios, o segundo e o terceiro [zwischen zwei Jahrtausenden, dem zweiten und dem dritten]". ' Ora, além de compreender que seu Zaratustra comunica algo inteiramente novo no âmbito dos valores humanos, soma-se também o fato de que Nietzsche conseguiu concluir um primeiro esboço da obra que visava a "transvaloração de todos os valores" - algo que não chega a ser mencionado na carta ao Barão de Seydlitz. De outra parte, é em um rascunho de carta elaborado provavelmente também em I2 de fevereiro de I888, cujo destinatário seria Overbeck, que o filósofo dá a entender porque uma parte sua (e não a totalidade) havia retornado do estado de isolamento no qual se encontrava:

Aqui somente três palavras para anunciar algo bom. Sobreveio uma grande tranquilidade e alívio; uma crise larga, extremamente dolorosa, na qual minha inteira sensibilidade esteve sublevada, parece resolvida e arquivada. Expressando-o como factum brutum: a primeira redação da minha transvaloração de todos os valores está terminada. A concepção global da obra foi, com diferença, a tortura maior que vivi, uma verdadeira enfermidade. ${ }^{8}$

De fato, Nietzsche havia concluído uma "primeira redação" para a elaboração da obra A vontade de potência: tentativa de transvaloração de todos os valores." Tratava-se, todavia, não de um livro acabado, mas de um conjunto de notas que

6 Carta a Reinhart von Seydlitz de I2 de fevereiro de I888, кSB 8.248.

7 Carta a Carl Spitteler de Io de fevereiro de I888, кSB 8.247.

8 Carta a Franz Overberck [Rascunho, por volta de I3 de fevereiro de I888], кSв 8.250.

9 Este conjunto de anotações compóem os "dois Cadernos w II 1 e w II 2, bem como as cinquenta e oito primeiras páginas do Caderno w II 3 ”, conforme a edição crítica das obras completas de Nietzsche editadas por Colli e Montinari, ou seja, trata-se do conjunto de fragmentos póstumos do volume que compreende o período do Outono de I887 a março de I888. 
serviriam de base para cada um dos quatro volumes que ele tencionava elaborar. Embora esclarecedor, o rascunho de carta que Nietzsche não chega a enviar omite uma confissão, que ele por fim revela na carta dirigida a Heinrich Köselitz em I3 de Fevereiro de I888: "Terminei a primeira redação de minha Tentativa de uma Transvaloração: foi, dito de modo breve, uma tortura, e ainda não tenho, de modo algum, a coragem que é requerida. Quando passem dez anos quero fazê-lo melhor" .

A partir tanto do rascunho de carta a Overbeck quanto da carta enviada a Köselitz, é possível compreender porque Nietzsche dissera que uma parte sua havia se convertido em algo "oculto", sendo ele "incapaz de buscá-lo": embora tenha conseguido terminar um "primeiro esboço" de sua obra, algo que lhe trouxera a certeza de que talvez não fosse "impossível” ser ele não somente o "primeiro filósofo" de uma época, mas sobretudo "algo decisivo e fatal" que se encontra entre o final do segundo milênio e o início do terceiro, o fato é que ele não se sente em condições para elaborar e publicar a obra que anunciara na Genealogia da Moral. É importante notar também que, ao receber a carta em Veneza, Köselitz não consegue compreender se Nietzsche pretende ou não publicar esta "primeira redação" de sua obra — algo que ele pergunta ao filósofo em uma missiva datada de 17 de fevereiro de i888. A resposta de Nietzsche vem no último domingo do mês de fevereiro, numa nova carta ao amigo na qual ele volta a insistir, elucidando: "[...] esse escrito era para mim; durante todo o inverno, desde agora e sem interrupções, quero fazer para mim tal escrito — está propriamente excluida a ideia de 'publicação' ". "

Com a saúde bastante debilitada após trabalhar rigorosamente durante todo o inverno em suas anotações, Nietzsche decide partir para Turim. Cidade italiana que lhe havia sido recomendada já há algum tempo por seu amigo Köselitz (a quem Nietzsche escreve em 3I de março de I888 comunicando que acatara a sugestão $)^{\mathrm{I2}}$, ela representa naquele momento uma "nova tentativa de suportar este tempo de primavera que para mim é tão inquietante e nocivo". ${ }^{13}$ Sua chegada em Turim após uma conturbada viagem ocorre no dia 5 de abril. Conhecemos bem o quanto o filósofo apreciará a cidade que, para ele, está impregnada por um gosto aristocrático, proveniente "do século xvıı" — tal como deixa registrado já

IO Carta a Heinrich Köselitz de I3 de fevereiro de I888, кSв 8.252.

II Carta a Heinrich Köselitz de 26 de fevereiro de I888, KSB 8.264.

I2 Carta a Heinrich Köselitz de 3I de março de I888, кSв 8.280.

I3 Carta a Franziska Nietzsche de 3I de março de I888, KsB 8.283. 
na primeira carta que de lá escreve a Köselitz no dia 7 de abril (e nas seguintes, a diversos correspondentes).

Recobrando forças em Turim, o ainda pouco conhecido autor da Genealogia da Moral ali recebe uma correspondência que age positivamente sobre seu estado de ânimo. Nela, Georges Brandes lhe informa que está dando um curso sobre o "filósofo alemão" na Universidade de Copenhague. Mostrando seu contentamento em resposta enviada ao crítico literário dinamarquês em io de abril, Nietzsche também aproveita a ocasião para enviar novos resumos das obras que publicara até então, assim como acrescenta uma notícia biográfica a seu respeito. ${ }^{\mathrm{I}}$ É também em Turim que chega desde Nova York a notícia de que um admirador do Zaratustra quer dar a conhecer sua obra filosófica para o público dos Estados Unidos, ao que o filósofo também responde com apreço. ${ }^{\text {IS }}$

Todo esse início de reconhecimento internacional de sua obra, somado à recuperação de sua saúde na cidade de gosto aristocrático, contribuem para que Nietzsche algumas semanas depois perceba que a multiplicidade de sua filosofia guarda uma unidade. ${ }^{16}$ Ademais, entre a partida de Nice e parte da estadia em Turim, surgem nos seus cadernos de anotações [da Primavera de I888] diversos novos esboços do projeto de $A$ vontade de potência. Tentativa de transvaloração de todos os valores. ${ }^{17}$ É também em Turim, como sabemos, que ele conclui no

I4 $\mathrm{O}$ procedimento para esclarecer seu percurso intelectual e biográfico iniciara já com a primeira carta enviada a Brandes em 2 de dezembro de 1887.

I5 Carta a Ernst Wilhelm Fritzsch, [pouco depois de I4 de abril de I888], кSв 8.296.

I6 Carta a George Brandes de 4 de maio de I888, кSB 8.310.

I7 No caderno [w II 5] da Primavera de I888, três são os projetos: "A vontade de potência. Tentativa de uma transvaloração de todos os valores. Primeira parte. O que vem da força. Segunda parte. O que vem da fraqueza. Terceira parte. E de onde viemos nós? Quarta parte. A grande escolha" (Fragmento póstumo I4 [78] da primavera de I888, KSA I3.257); "A vontade de potência. Tentativa de uma transvaloração de todos os valores. I. Crítica dos valores admitidos até agora. II. O novo Princípio de Valor. Morfologia da 'vontade de potência'. III. Problema do valor de nosso mundo moderno: medido segundo esse Princípio. IV. A grande guerra" (Fragmento póstumo I4 [136] da primavera de I888, KSA I3.320); "A vontade de potência. Tentativa de uma transvaloração de todos os valores. Primeiro capitulo: o mundo verdadeiro e o mundo aparente. Segundo capitulo: como um tal engano foi possível? Que significa a vontade de entender mal a vida? Crítica dos filósofos, enquanto tipos da decadência. Terceiro capitulo. A moral enquanto expressão da decadência. Crítica do altruísmo, da compaixão, do cristianismo, da dessensualização. Quarto capítulo. Não há indícios para uma posição contrária? I. Pagãos na religião; 2. "a arte”; 3. O estado. A guerra contra eles: o que sempre conspira contra... Quinto capitulo. Critica da atualidade: de onde ela pertence? Seu emblema niilista. Seus tipos afirmativos: é necessário compreender o fato monstruoso, que existe uma boa consciência da ciência... Sexto capitulo. A vontade de potência, como vida. Sétimo capitulo. Nós, os hiperbóreos. Somente posiçóes absolutas, por exemplo, a felicidade!! Por exemplo, a história monstruosa de gozo e triunfo no final, não ter claro nenhum "sim" e "não"... salvação da dúvida! (Fragmento póstumo I4 [I56] da primavera de I888, KSA I3.340]. O caderno w II 6a, também da primavera de I888, trás 
final de maio $O$ Caso Wagner, bem como encontra disposição para fazer novas leituras, entre as quais a tradução francesa do Código de Manu (obra que mais tarde ocupará um lugar estratégico em $O$ Anticristo). Todavia, apesar da proveitosa estadia na cidade italiana à margem do rio Pó, Nietzsche já há algum tempo estava decidido a passar o verão em Sils-Maria (lugar que descobrira em I88I e para onde retornara sempre nesta mesma estação desde I883).

Partindo para a Suíça em 6 de junho de I888, o filósofo não somente faz uma viagem difícil, com novas complicações de saúde, como não encontra, ao chegar, o clima que desejava: ao contrário dos anos anteriores, Sils-Maria ainda está envolta por neve, por um "ar úmido, sufocante, de degelo". ${ }^{18}$ Novamente debilitado, ele persiste em fazer resumos de suas obras para enviar ao estudioso que quer divulgá-las nos Estados Unidos. ${ }^{19}$ Mas a inclemência do mau tempo e o fato de estar doente há um mês acaba por abater o ânimo de Nietzsche, que em desoladora confissão a Overbeck julga que sua saúde parece não ter mais recuperação em face dos últimos dez anos de sucessivas crises. ${ }^{20}$ Não obstante as más condiçôes meteorológicas em Sils-Maria (que levam hóspedes mais idosos a deixarem a região neste período), ele consegue concluir na metade de julho uma primeira revisão das provas de $O$ Caso Wagner ${ }^{21}$, bem como continua a realizar novos esboços do projeto de sua obra capital. ${ }^{22}$ Todavia, embora busque até mesmo melhorar sua alimentação na tentativa de encontrar forças para atravessar o restante do mês de julho, Nietzsche fragiliza-se cada vez mais nos

o seguinte projeto: "A vontade de potência. Tentativa de uma transvaloração de todos os valores. Primeiro livro. Os valores de declínio [...]. Segundo livro. Por que somente os valores de declínio vieram a ser dominantes [...]. Terceiro livro. A modernidade como ambiguidade de valores [...]. Quarto livro. O valor do futuro (enquanto expressão de uma espécie mais forte de homem): que deve começar a existir" (Fragmento póstumo Is [IOO] da primavera de I888, KSA I3.466).

I8 Carta a Heinrich Köselitz de I4 de junho de I888, кsB 8.33I.

I9 Carta a Karl Knortz de 2i de junho de I888, кsв 8.339.

20 Carta a Franz Overbeck de 4 de julho de I888, кsB 8.347.

2I Cf. Carta a Constantin Naumann de I6 de julho de I888, кSB 8.35I.

22 No caderno [w II 7a] da primavera/verão de I888 surge a seguinte anotação: “A vontade de potência. Tentativa de uma transvaloração de todos os valores. I. Psicologia do erro. I) Confusão entre efeito e causa; 2) Confusão entre a verdade e isso em que cremos verdadeiro; 3) Confusão entre a consciência e a causalidade; 4) Confusão entre a lógica e o princípio de realidade; II. Os valores falsos. I) A moral enquanto falsidade; 2) A religião enquanto falsidade; 3) A metafísica enquanto falsidade; 4) As ideias modernas enquanto falsidade. Tudo isso condicionado pelas quatro categorias do erro. III. O critério de verdade. I) A vontade de potência. 2) Sintomatologia da decadência. 3) Para uma fisiologia da arte. 4) Para uma fisiologia da politica; IV. Conflito dos falsos e dos novos valores. I) Necessidade de um movimento duplo; 2) Utilidade do movimento duplo; 3 ) Os fracos; 4) Os fortes. I6 capítulos: 37 páginas" (Fragmento póstumo I6 [86] da primavera/verão de I888, KSA I3.5I5]. 
dias seguintes, a exemplo do esforço que faz para rebater o tom por demais pessoal, "infinitamente pequeno", que encontra numa longa carta recebida de Carl Fuchs ${ }^{23}$, e ainda por preocupações de toda ordem, entre elas a de sua situação financeira, tal como confessa à sua mãe ao contar-lhe que já há algum tempo na Basileia "fazem em realidade mais do que o necessário", uma vez que a data final de sua pensão prescrevera em I886. ${ }^{24}$

Após dois meses nas altas montanhas da Suíça, o criador do Zaratustra atravessa também a maior parte do mês de agosto de I888 mergulhado em crises sucessivas. Desculpa-se então perante seus amigos com a repetida justificativa de que "os filósofos, quando estão enfermos, fazem como os animais, emudecem, se escondem em sua caverna". ${ }^{25}$ Tal como seu Zaratustra, Nietzsche somente deixa sua "caverna" neste período quando alguém vai ao seu encontro, algo que ocorre nas três primeiras semanas de agosto quando Julius Kaftan (professor de teologia na Basileia durante os anos de 1874 a 1883 e depois em Berlin) ${ }^{26}$ vem lhe visitar. Após a partida de Kaftan, com quem mantivera diariamente longas conversações teológicas, Nietzsche reconhece em carta de 22 de Agosto de 1888 que sua companhia lhe foi agradável, visto ser ele "um dos teólogos mais simpáticos que conheço" ${ }^{27}$, mas também queixa-se que atravessa por fortes períodos de insônia e considera que o verão “'foi por água abaixo' ['ins Wasser gefallen']". ${ }^{28}$ Apesar dos dessabores, o filósofo ainda consegue redigir e enviar ao seu editor o "Epílogo" de O Caso Wagner, pedindo-lhe na mesma carta que a prova do livro seja remetida a Köselitz, para uma última revisão. ${ }^{29}$

Insone de modo cada vez mais intenso, no último domingo do mês de agosto de I888, dois movimentos simultâneos de Nietzsche são importantes para que possamos compreender, em parte, porque no início do mês seguinte ele finalmente irá dedicar-se à tarefa da transvaloração de todos os valores. A saber: em 26 de agosto ele esboça num parco caderno de notas aquele que seria seu último projeto da obra $A$ vontade de potência (note-se que em comparação com os demais cadernos nos quais registrava seus pensamentos desde o início de I888,

23 Cf. Carta a Franz Overbeck de 20 de julho de I888, кsв 8.36I.

24 Carta a Franziska Nietzsche de 24 de julho de I888, кsв 8.367.

25 Carta a Emily Fynn de II de agosto de I888, кsB 8.386.

26 Julius Kaftan, que ficou hospedado em Sils-Maria com sua esposa durante três semanas, escreverá mais tarde a propósito do encontro com Nietzsche o texto "Aus der Werkstatt des Uebermenchen". In: Deutsche Rundschau 32 (1905), pp. 90-IIO e 237-260.

27 Carta a Franziska Nietzsche de 22 de agosto de I888, кsв 8.395.

28 Carta a Meta von Salis de 22 de agosto de I888, KSB 8.397.

29 Cartão Postal a Heinrich Köselitz de 24 de agosto de I888, кsв 8.398. 
este é um volume com apenas 17 anotações $)^{30}$; e, no mesmo dia, escreve duas longas cartas a Carl Fuchs, nas quais trata de questôes relativas ao "Fraseio" e acerca da diferença entre a "ritma antiga e a ritma bárbara". ${ }^{31}$ Ora, a diferença colossal entre a seriedade exigida pela tarefa da transvaloração de todos os valores e a perda de tempo com questôes menores como a do "fraseio" demarcam em Nietzsche uma linha divisória.

Neste sentido, é importante aqui atentar para o fato de que após enviar a missiva a Carl Fuchs, a última carta que Nietzsche redige no mês de agosto é endereçada à sua mãe. Nela, informa que está "novamente em plena atividade" e "espera continuar assim um tempo", pois o trabalho que exige "longa preparação" e que "deveria ter sido realizado neste verão", foi "literalmente por 'água abaixo". Disposto a continuar trabalhando, apesar do "dano irreparável que causou este horrível verão", o filósofo pede em sua carta que lhe enviem "Uma caneta Sönneckens bico de pena, n. ${ }^{\circ}$, grande ${ }^{\prime 32}$ e, em vertiginosa atividade intelectual, conclui logo no início de setembro de 1888 a redação do Crepúsculo dos Ídolos (obra inicialmente pensada sob o título Ociosidades de um psicólogo) ${ }^{33}$, toma coragem para empreender a "tremenda tarefa da transvaloração [Aufgabe der Umwerthung] ${ }^{\prime 34}$, esboça o projeto desta tarefa em quatro livros" ${ }^{35}$ e redige, no dia

30 Trata-se do caderno [mp xviI 5. Mp xvi 4b] de Julho-agosto de I888. A última anotação neste caderno é: "Esboço do plano de: $A$ vontade de potência. Tentativa de uma transvaloração de todos os valores — Sils Maria, último domingo do mês de agosto de I888. Nós Hiperbóreos. - Colocação da pedra fundamental do problema. Primeiro livro: "O que é a verdade?". Primeiro capitulo. Psicologia do erro. Segundo capitulo. Valor da verdade e mentira. Terceiro capitulo. A vontade de verdade (justificada somente no valor afirmativo da vida). Segundo livro: Origem dos valores. Primeiro capitulo: Os metafísicos. Segundo capitulo: Os homines religiosi. Terceiro capitulo: Os bons e o Melhoradores. Terceiro livro: Conflito dos valores. Primeiro capitulo. Pensamentos sobre o cristianismo. Segundo capitulo. Sobre a psicologia da arte. Terceiro capitulo. Para a história do niilismo europeu. Distração-de-Psicólogos. Livro quarto: O grande meio-dia. Primeiro capitulo. O princípio da vida "hierárquica". Segundo capitulo. Os dois caminhos. Terceiro capitulo. O eterno retorno" (Fragmento póstumo I8 [I7] de Julho/agosto de I888, KSA I3.537).

3I Sobre o contexto desta correspondência com Carl Fuchs, ver Rubira, 20I3, pp. I34-I49; texto posteriormente ampliado e publicado em francês em 2015, pp. 275-293.

32 Carta a Franziska Nietzsche de 30 de agosto de I888, кsB 8.406.

33 Em Ecce Homo, Nietzsche registra que concluiu o Crepúsculo dos Ídolos em "tão poucos dias que hesito em dizer seu número" (Ecce Homo, "Crepúsculo dos Ídolos", \ I, KsA 6.354. Tradução conforme Paulo César de Souza (Nietzsche, I995). A partir de agora indicado como PCs.

34 Nietzsche também registra em Ecce Homo que, ao finalizar o Crepúsculo dos Ídolos, "sem perder um só dia, acometi a tremenda tarefa da transvaloração" (Ibid, $\S_{3}$, KSA 6.355, tradução de PCS).

35 Num pequeno dossiê com folhas soltas [mp xvil 6. Mp xvi 4c. w II 9b. w II 6b] de Setembro de I888, Nietzsche escreve: "TransvaloraÇão de todos os valores. Primeiro livro. O Anticristo. Tentativa de uma crítica do Cristianismo. Segundo livro. O espirito 
3 de setembro de i888, o prefácio do primeiro livro, ou seja, de $O$ Anticristo ${ }^{36}$ movimentos que, em sequência lógica e cronológica podem ser percebidos não sem alguma dificuldade tanto em suas anotações de setembro de I888 quanto mais tarde em Ecce Homo, eles implicam numa mudança de rumo decisiva que somente adquire clareza em sua correspondência.

Após conceber o projeto da Transvaloração de todos os valores articulado em torno de três livros críticos (que visariam a destruição dos valores até então estabelecidos) e de um quarto opúsculo no qual apresentaria a sua "filosofia do eterno retorno" (a nova medida de valor para todos os valores) ${ }^{37}$, e enquanto trabalha intensamente na redação de $O$ Anticristo, Nietzsche escreve uma primeira carta no dia 6 de setembro de i888, endereçada justamente a Carl Fuchs. Nela, é possível perceber pela primeira vez uma mudança radical de tom em relação à tarefa da transvaloração:

Nos próximos dias deixarei Sils. Já que, todavia, necessitarei recolhimento profundo durante muito tempo, desaparecerei uma vez mais, em conformidade com minha práxis monacal, para visitas de todo o tipo - cartas incluídas. Ante mim está um pacote de cartas que não li: temo que entre elas estejam duas suas. — E por último, não lhe oculto minha suspeita: não tratam estas cartas do sagrado "Fraseio"? Neste caso, haveria que ponderar com toda a seriedade se a enviaram para um endereço equivocado? Cartas sobre o "fraseio" ao filósofo da Transvaloração de todos os valores!... ${ }^{38}$

Ora, se lembrarmos do esboço da carta para Overbeck escrito em I3 de Fevereiro de I888 no qual Nietzsche comunicava que conseguira concluir uma primeira redação da Transvaloração e da missiva dirigida no mesmo dia a Köselitz para dizer-lhe que necessitaria ainda de dez anos para elaborar melhor esta sua

Livre. Crítica da filosofia como movimento niilista. Terceiro livro. O Imoralista. Crítica da espécie mais funesta de ignorância, a moral. Quarto livro. Dioniso. Filosofia do eterno retorno (Fragmento póstumo I9 [8] de Setembro de I888, KSA 13.545).

36 Em Ecce Homo, o filósofo não elabora um capítulo para abordar O Anticristo, embora o livro já estivesse concluído. Todavia, no capítulo sobre o Crepúsculo dos Ídolos, o terceiro parágrafo é inteiramente dedicado a tratar da tarefa da transvaloração. Referindo-se a esta tarefa (cujo primeiro livro seria, justamente, $O$ Anticristo), Nietzsche ali informa: "O prólogo foi escrito em 3 de setembro de i888: quando naquela manhã saí ao ar livre, após a redação, dei com o mais belo dia que a Alta Engandina jamais me mostrou” (Ecce Homo, "Crepúsculo dos Ídolos", \$3, KSA 6.355, tradução de PCS).

37 Sobre o eterno retorno do mesmo como nova medida de valor ver: Rubira, 20Io, capítulo II.

38 Carta a Carl Fuchs de 6 de setembro de I888, кsв 8.409. 
obra, então a carta a Carl Fuchs (redigida a partir de um rascunho prévio cujo tom crítico era bem mais severo) ${ }^{39}$ representa o primeiro momento no qual Nietzsche, após sete meses de silêncio, assume-se como o filósofo da transvaloração de todos os valores [Philosophen der Umwerthung aller Werthe]. Tudo isto ganha ainda mais elucidação em uma missiva elaborada no dia seguinte (7 de setembro de I888) para Meta Von Salis, cujo conteúdo, ademais, joga luz sobre todos os movimentos realizados por ele nas últimas semanas:

Nos últimos tempos trabalhei muito, - até o grau de que tenho motivos para desmentir o suspiro de minha última carta pelo "verão que se foi por água abaixo". Inclusive consegui algo mais, algo que não confiava que fosse capaz de fazer... A consequência que tive foi, ademais, que minha vida caiu, nas últimas semanas, em certa desordem. Levantei-me várias vezes às duas da noite "empurrado pelo espírito" e me colocava a escrever o que acabava de me ocorrer [...]. O dia três de Setembro foi um dia muito curioso. De madrugada escrevi o prólogo para minha Transvaloração de todos os valores, o prólogo mais orgulhoso que talvez se tenha escrito até agora. Depois sai - e veja você! O dia mais belo que vi em Engandina, - uma potência luminosa de todas as cores, um azul no lago e no céu, uma claridade do ar, totalmente inauditas [...]. Pela tarde passeei dando a volta inteira em torno do lago de Silvaplana: esse dia permanecerá provavelmente em minha memória. — [...] No próximo ano irei me decidir a imprimir minha Transvaloração de todos os valores, o livro mais independente que existe... Não sem antes fazer grandes reparos! O primeiro livro se intitula, por exemplo, $O$ Anticristo. ${ }^{40}$

Como já apontei anteriormente ${ }^{4 \mathrm{I}}$, Nietzsche contará parte disto em Ecce Homo no capítulo dedicado ao Crepúsculo dos Ídolos, em cuja terceira sessão ele trata da tarefa da transvaloração e refere-se ao Anticristo de modo indireto (obra que, ademais, já estava concluída no período de redação de Ecce Homo, mas para a qual ele, ao contrário de seus demais livros, não dedica um capítulo em sua autobiografia intelectual justamente pelo fato de que deixaria para o ano seguinte o anúncio deste primeiro livro da transvaloração de todos os valores).

39 Eis um trecho: "Estimado amigo, você deve por fim ponderar que o fraseio não é nada que me interesse: e que eu, por estar comprometido com você e por uma certa objetividade habitual com coisas desagradáveis, abstive-me de fazer o que qualquer outra pessoa em meu lugar há tempos teria feito: a saber, dizer: 'vá ao diabo!'. Porém agora estou sensivelmente em um caso de legítima defesa. Resisto [com] todo o meu corpo a quem me invada com cartas. Que tem a ver minha existência mesclada com coisas bastante sérias com semelhantes questões absurdas como o 'fraseio'!" (Carta a Carl Fuchs, [Rascunho, setembro de I888], KSB 8.408).

40 Carta a Meta Von Salis de 7 de setembro de 1888, кSB 8.4II.

4I Ver notas 32, 34 e 36. 
É simbólico que Nietzsche, ademais, na medida em que conclui o prefácio de O Anticristo, caminhe em círculo ao redor do lado de Silvaplana, lugar onde há sete anos tivera a "visão" da repetição cíclica de todos os acontecimentos. Embora este gesto reforce o vínculo existente entre a tarefa da transvaloração e o pensamento do eterno retorno do mesmo, o filósofo continua com o receio de não ser compreendido. Insistindo na ideia de publicar a obra da transvaloração no ano seguinte, ele também menciona ao seu editor em carta do dia 7 de setembro acerca do envio do manuscrito que recentemente concluíra:

Acabo de enviar-lhe o manuscrito mais limpo de todos os que jamais lhe enviei. Trata-se de um escrito que, no que se refere à apresentação tipográfica, deve ser totalmente gêmeo ao Caso Wagner. Seu título é Ociosidade de um psicólogo. Necessito publicá-lo agora porque para o fim do próximo ano provavelmente teremos que proceder a edição de minha obra principal, a Transvaloração de todos os valores. ${ }^{42}$

Em Sils-Maria, nas proximidades do lago de Silvaplana, enquanto trabalha sem cessar no primeiro livro da transvaloração, Nietzsche volta a escrever a Carl Fuchs. Nesta missiva, ele continua a detalhar que há algumas semanas lançara-se numa tarefa para a qual meses antes não se julgava capaz — tarefa em relação a qual ele também passa a demonstrar algum receio quanto à recepção que sua obra poderia ter no ano seguinte:

Nas últimas semanas estive inspirado do modo mais estranho: de maneira que algumas das coisas para as quais não me considerava capaz, em uma manhã, como de maneira inconsciente, estavam já prontas. Isto ocasionou certa desordem e produziu certas exceçōes em minha forma de vida: levantava-me (ou saltava) às 2 da noite, para escrever algo, "empurrado pelo espírito" [...]. - Incrível, porém certo: enviei hoje para a impressão o manuscrito mais cuidado, mais limpo e trabalhado que jamais redigi - não desejo calcular de nenhum modo em quão poucos dias ele tomou corpo. O título é bastante amável, Ociosidade de um psicólogo - e o conteúdo é dos mais inquietantes e radicais que existem, ainda que esteja escondido entre muitas finesses [sutilezas] e atenuações. É uma perfeita introdução de conjunto à minha filosofia: - o próximo que virá na continuação é a Transvaloração de todos os valores (cujo primeiro livro está quase terminado). Teremos verificado em saber até que grau é possível hoje a "liberdade de pensamento" propriamente dita: tenho o lúgubre pressentimento de que depois de sua publicação me perseguirão da maneira mais elegante. ${ }^{43}$

Como a seguir ficará esclarecido, Nietzsche de fato reenviou o manuscrito

42 Carta a Constantin Georg Naumann de 7 de setembro de I888, KsB 8.4II.

43 Carta a Carl Fuchs de 9 de setembro de I888, кSB 8.4I4. 
de Ociosidade de um psicólogo ao seu editor no dia 9 de setembro. Mas o que é importante reter nesta carta é que ele considera este livro, de introdução ao conjunto de sua filosofia, como sendo aquele que possibilitaria preparar o leitor para a obra da Transvaloração. Quatro dias mais tarde, em carta de I2 de setembro de 1888 a seu amigo Köselitz, ele volta a mencionar que o livro Ociosidades de um psicólogo servirá como algo introdutório e prévio à transvaloração, informando também que o primeiro livro está "quase terminado":

Faz poucos dias que voltei a enviar ao senhor C. G. Naumann um manuscrito, com o título Ociosidade de um psicólogo. Por debaixo deste título inofensivo se esconde uma síntese, lançada de maneira muito atrevida e precisa, de minhas heterodoxias filosóficas essenciais: de modo que este escrito pode servir para iniciar e para abrir o apetite com respeito a minha Transvaloração de todos os valores (cujo primeiro livro está quase terminado). [...] Este escrito, que se apresenta em tudo como gêmeo do Caso Wagner (se bem que tem o dobro de força) tem de sair o mais rápido possível: porque necessito de um tempo até a publicação da Transvaloração (- esta, com uma seriedade rigorosa e a mil milhas de todas as tolerâncias e amabilidades). ${ }^{44}$

Em novas cartas escritas em I3 de setembro de I888, encaminhadas desta vez a Georg Brandes e ao Barão de Seydlitz, o filósofo da transvaloração continua a mostrar seu receio de que o persigam a partir do momento em que ele publique O Anticristo e os demais livros de sua obra capital:

Dentro de dois meses aguarde algo filosófico: com o título muito benévolo de Ociosidade de um psicólogo digo a todo o mundo cortesias e descortesias [...]. Em relação ao assunto principal, tudo isto não representa mais do que descansos com relação a esse assunto principal: que se chama: Transvaloraçāo de todos os valores - A Europa necessitará inventar uma Sibéria a mais para enviar para lá o autor desta tentativa de valoração [Werth-Tentative]..$^{45}$ Minha economia interna está total e absolutamente ao serviço de um assunto extremo, que, como título bibliográfico, para dizê-lo em cinco palavras, é a Transvaloração de todos os valores. Tenho refletido frequentemente sobre as medidas que se inventarão contra mim a tolerância da Europa: construir expressamente uma pequena Sibéria [...] para poder banir a mim a essa Sibéria.... ${ }^{46}$

Afora a preocupação crescente em torno das consequências que adviriam com a publicação de uma obra tão crítica em relação aos valores até então estabelecidos, é de suma importância observar na carta a Brandes que Nietzsche se refere à

44 Carta a Heinrich Köselitz de I2 de setembro de I888, кsв 8.4I7.

45 Carta a Georg Brandes de I3 de Setembro de I888, кSB 8.420.

46 Carta a Reinhart von Seydlitz de I3 de setembro de I888, кSB 8.424. 
transvaloração como uma "tentativa de valoração", o que implica em que não se trata somente de inverter os valores, mas de ir além deles, com base em um novo critério axiológico. Neste sentido, se em Para além de Bem e Mal ele já indicara que há dois milênios houve uma transvaloração judaico-cristã de todos os valores e mostrara na Genealogia da moral como houve a mudança dos valores nobres da antiguidade, apontando também nestas obras a necessidade de se promover uma nova transvaloração, é porque sabia (tal como já observei) que somente uma nova medida de valor para todos os valores mudaria o rumo da humanidade. É por esta razão que em carta a Paul Deussen, escrita em I4 de Setembro de i888, Nietzsche, além de informar-lhe que ele receberá o Caso Wagner (considerado como um escrito polêmico de estética) e que está sendo impressa a obra Ociosidades de um psicólogo (manuscrito que representaria toda a sua ortodoxia filosófica), ele volta a insistir na ideia de que a tarefa da transvaloração que visa opõe-se à transvaloração judaico-cristã operada há dois milênios:

- Ao fim das contas estes dois escritos [O Caso Wagner e Ociosidades de um psicólogo] não são senão verdadeiros descansos em meio de uma tarefa desmesuradamente difícil e decisiva, que, se se compreende, partirá em dois a história da humanidade. O sentido da mesma está resumido em cinco palavras: Transvaloração de todos os valores [...]. $\mathrm{O}$ primeiro livro deste programa já está quase pela metade terminado. ${ }^{47}$

É, portanto, por conceber a tarefa crítica da transvaloração (crítica do cristianismo, da filosofia e da moral) a partir de uma nova medida de valor (Dioniso. Filosofia do eterno retorno), que Nietzsche está convicto de que sua "tentativa de valoração" representa algo novo, capaz de "dividir em dois a história da humanidade" (frase, aliás, repetida literalmente na penúltima seção do capítulo "Por que sou um destino" de Ecce Homo). Tendo a certeza de que até ele jamais alguém havia realizado uma ofensiva radical contra os valores cristãos, Nietzsche faz questão de dizer a seu amigo Franz Overbeck também no mesmo dia I4 de setembro de I888:

É-me permitido falar de mim? Em relação ao tema principal sinto agora, mais do que nunca, a grande calma e a grande certeza de estar fazendo meu caminho e inclusive de encontrar-me próximo de uma grande meta. Para minha própria surpresa, tenho já concluído em sua forma definitiva a metade do primeiro livro de minha Transvaloração de todos os valores $[\ldots]$ - o primeiro livro, seja dito entre nós, chamase $O$ Anticristo, e posso jurar que tudo o que até agora se pensou e foi dito para a crítica ao cristianismo é, em comparação, mera coisa de crianças. ${ }^{48}$

47 Carta a Paul Deussen de I4 de setembro de I888, кsв 8.426.

48 Carta a Franz Overbeck de I4 de setembro de I888, кSв 8.434. 
À véspera de deixar Sils-Maria, cuja viagem estava prevista para Is de Setembro, mas que somente ocorrerá cinco dias mais tarde, é possível também perceber que o filósofo mantém a posição, junto ao seu editor, de que após a publicação de Ociosidades de um psicólogo exista o intervalo de um ano para dar a conhecer a obra da transvaloração. ${ }^{49}$

Novamente em Turim a partir do dia 2I de Setembro de $1888^{50}$, Nietzsche volta a trabalhar no manuscrito de $O$ Anticristo. Menos de uma semana depois, ele escreve a seu amigo Heinrich Köselitz para comunicar sua decisão em alterar o título de Ociosidade de um psicólogo para Crepúsculo dos Ídolos - ou como se filosofa com o martelo, voltando também a repetir que o primeiro livro da Transvaloração "está quase terminado". sI Ora, sabemos que três dias mais tarde, no momento em que finaliza o prefácio para o Crepúsculo dos Idolos, ele dá por concluído O Anticristo: "Turim, em 30 de setembro de I888, dia em que foi terminado o primeiro livro da transvaloração de todos os valores" "', algo que é confirmado também no final de O Anticristo, obra em cujo final ele estabelece uma "Lei contra o Cristianismo", proclamada exatamente no "dia primeiro do ano um (30 de setembro de I888 do falso calendário)". ${ }^{33}$

Se nove meses atrás o "peso" da existência do filósofo "pesava" do modo mais intenso ${ }^{54}$, ao concluir o primeiro livro da tarefa da transvaloração ele sentese transformado, pois, como dirá em breve: a vida, ao exigir dele o mais pesado, tornou-se também a mais leve $e^{\varsigma s}$. É neste estado de espírito jovial, de quem após

49 Em sua carta a Naumann, observa: "Fiquei surpreso, porém mais contente, em saber que você em seguida começou a imprimir a Ociosidade. [...] Para poder publicar esta obra excepcionalmente séria, a Transvaloração de todos os valores, se necessita, em realidade, de pelo menos um ano de distância, de tempo que transcorra em relação a publicações anteriores." (Carta a Constantin Naummann de I8 de setembro de i888, кSB 8.44I).

50 Além da correspondência, Nietzsche fala de sua chegada em Turim em Ecce Homo, "Crepúsculo dos Ídolos", \$3, KSA 6.355.

5I Carta a Heinrich Köselitz de 27 de setembro de I888, кSB 8.443.

52 Cf. Crepúsculo dos Ídolos, "Prefácio", ksa 6.58.

53 Para uma compreensão do significado de $O$ Anticristo ver: GEN, 20I6, pp. 83-88.

54 Cf. Cartão Postal a Franz Overbeck de 28 de dezembro de I887, кsв 8.216.

55 Conforme escreve em Ecce Homo: "A vida tornou-se-me leve [leicht], a mais leve [leichtesten], quando exigiu de mim o mais pesado [Schwerste]. Quem me viu nos últimos setenta dias deste outono, quando sem interrupção fiz coisas de primeira ordem [...], com uma responsabilidade para com todos os milênios vindouros, não terá percebido um traço de tensão em mim, antes transbordante frescor e alegria". (Ecce Homo, "Porque sou tão sábio", \$ IO, KSA 6.297, tradução de PCS). 
uma "grande vitória", vive a "ociosidade de um deus à margem do [rio] Pó" ", que ele escreve no dia 4 de Outubro de I888 a primeira carta na qual comunica o referido acontecimento. Estando na Itália, é simbólico que Nietzsche escolha justamente a condessa Malwida von Meysenburg para dividir com ela a sua alegria acerca da tarefa da transvaloração: afinal, após sua grande decepção com o Wagner no Festival de Bayreuth em I876, fora ela quem o convidara para fazer uma viagem a Sorrento (viagem empreendida a partir de outubro e que implicaria numa mudança de rumo de sua filosofia, dando ele à luz dois anos depois a obra Humano, demasiado Humano). ${ }^{57}$

Logo na abertura de sua carta, Nietzsche então diz para a amiga que acabara de pedir ao seu editor para que enviasse para ela três exemplares de $O$ Caso Wagner e, após tecer consideraçôes sobre o alcance e recepção deste livro cujo subtítulo seria "um problema para músicos", por fim lhe comunica:

Redigi este pequeno escrito [O Caso Wagner] durante a primavera, aqui em Turim: neste meio tempo concluí o primeiro livro de minha transvaloração de todos os valores, - o acontecimento filosófico de todos os tempos [das größte philosophische Ereigniß aller Zeiten], com o qual a historia da humanidade se parte em dois. ${ }^{58}$

Tecendo também consideraçôes afetivas sobre sua amiga ao final da missiva a ela enviada, o filósofo também lhe comunica que lamenta que Paul Bourget não tenha domínio sobre assuntos de música, caso contrário lhe pediria para verter $O$ Caso Wagner para o francês. Todavia, ao contrário do que esperava, Malwida von Meysemburg parece fazer pouco caso acerca da importância e da singularidade da tarefa da transvaloração, não aprecia o tom da renovada crítica a Wagner e acha contraditório que Nietzsche fale em Paul Bourget, segundo ela um wagneriano e decadente absoluto.

Dias mais tarde, ao receber a carta de Malwida von Meysembug, Nietzsche decepciona-se. Tomado pela raiva por ela ter considerado levianamente Paul Bourget como um decadente, escreve-lhe primeiramente uma curta resposta no dia I8 de Setembro para dizer-lhe que "em questôes de décadence eu sou a instância

56 Trecho de um texto ainda mais detalhado em Ecce Homo acerca da alegria de Nietzsche por ter concluído o primeiro livro da transvaloração: “A 30 de setembro, grande vitória; o sétimo dia; ociosidade de um deus à margem do Pó. No mesmo dia escrevi o prólogo ao Crepúsculo dos Ídolos [...]. - Jamais vivi um tal outono, nem julguei possível algo semelhante sobre a Terra - um Claude Lorrain ao infinito, cada dia da mesma perfeição indomável. - " (Ecce Homo, "Crepúsculo dos Ídolos", \$3, KSA 6.355).

57 A este respeito ver: D’Iorio, 20I4, em particular a Introdução e o primeiro capítulo.

58 Carta a Malwida von Meysenbug de 4 de outubro de I888, кsB 8.447. 
suprema que existe sobre a terra" ${ }^{59}$ Antes, todavia, de decidir romper relaçôes com sua amiga, o filósofo escreve no mesmo dia uma carta a Franz Overbeck, na qual então tenta repartir com outro velho amigo a sua satisfação por ter finalizado o primeiro livro de sua tarefa da transvaloração, uma tarefa árdua cuja dimensão ele volta a destacar, insistindo:

Que o primeiro livro da Transvaloração de todos os valores esteja concluído, pronto para a impressão, é algo que eu expresso com um sentimento para o qual não tenho palavras. Serão quatro livros, que irão aparecer individualmente. Desta vez, como grande artilheiro, tenho medo de ter partido a história da humanidade em dois. ${ }^{60}$

Enquanto a carta a Overbeck percorre o rumo em relação ao seu destinatário (sabemos que Overbeck será aquele que, com cuidado, recolherá o manuscrito de O Anticristo alguns meses depois), Nietzsche toma a decisão de romper a amizade com Malwida von Meysenburg e, voltando a escrever-lhe no dia 20 de outubro, dá uma demonstração do que significa a transvaloração na prática:

Eu tenho suprimido pouco a pouco quase todas as minhas relaçóes humanas, acima do nojo [Ekel], por me tomarem por algo que eu não sou. Agora é sua vez [...]. Você não compreende nada da minha tarefa? Não sabe o que quer dizer Transvaloração de todos os valores? Por que Zaratustra considera o virtuoso como o homem mais funesto? Por que ele deve ser o aniquilador da moral? - Esqueceu que ele diz "despedacem, despedacem os bons e os justos"?

Muito ao contrário de estar com suas faculdades mentais alteradas pela crise que se aproxima, Nietzsche aqui está em absoluta consonância com aquilo que ele mesmo escrevera anos atrás. De outra parte, antes mesmo de desolar-se com a incompreensão de Malwida von Meysenburg, ele já havia decidido iniciar em Is de Outubro de I888 a redação da obra na qual tentaria fazer-se compreender: Ecce Homo. O que leva a tal decisão provém de algo bastante lógico: o fato de que, já há algum tempo, ele elabora para alguns de seus correspondentes esboços de sua autobiografia e resumos de suas obras. Soma-se a isto também a necessidade premente de apresentar-se a si mesmo como filósofo antes de publicar a sua obra da transvaloração. ${ }^{62}$ Poucos dias antes de concluir Ecce Homo, ele já esclarecia em

59 Carta a Malwida von Meysenburg de I8 de outubro de I888, кSв 8.452.

6o Carta a Franz Overbeck de I8 de outubro de I888, KGB 8.453.

6I Carta a Malwida von Meysenburg de 20 de outubro de I888, кsв 8.458.

62 Neste sentido, é clara a frase inicial do prefácio de Ecce Homo: "Na antevisão de que dentro em breve terei de me apresentar à humanidade com a mais difícil exigência que jamais lhe foi feita, parece-me indispensável dizer quem sou" (Ecce Homo, "Prefácio", \ I, KSA 6.257. Tradução conforme Rubens Rodrigues Torres Filho (Nietzsche, 1987). 
carta de 30 de Outubro de I888 a seu amigo Köselitz:

No dia do meu aniversário voltei a trabalhar em algo que parece que corre bem e que já está notavelmente adiantado. Chama-se Ecce Homo. Ou Como tonar-se o que se é. Trata, com grande audácia, de mim e de meus escritos anteriores: com ele não somente quero apresentarme antes do totalmente inquietante ato solitário da Transvaloração - mas gostaria de fazer de vez uma prova daquilo que em realidade posso arriscar, dadas as ideias alemãs em torno da liberdade de imprensa. Minha suspeita é que confisquem em seguida o primeiro livro da Transvaloração [...]. Ademais falo de mim mesmo com toda a "astúcia" psicológica e toda a serenidade possíveis - pois de modo algum gostaria de apresentar-me ante os seres humanos como profeta, como monstro ou como uma aberração moral. ${ }^{63}$

Mantendo suas preocupações em relação ao modo como possam receber o primeiro livro da transvaloração, $O$ Anticristo, mas também receoso de que este venha a ter uma recepção decepcionante tal como acontecera com Assim falava Zaratustra, Nietzsche escreve para seu editor logo após concluir Ecce Homo (obra que ele redigira entre is de Outubro e 4 de novembro de I888):

Estou convencido de que necessito de outro escrito, um escrito preparatório, para depois do prazo aproximado de um ano poder apresentar-me com o primeiro livro da Transvaloração [dem ersten Buche der Umwerthung]. Há que ser criada uma verdadeira tensão do contrário sucederá como com o Zaratustra [...]. - O novo escrito se intitula: Ecce Homo. Como torna-se o que se e..$^{64}$

Em novas cartas a Franz Overbeck e a Meta von Salis datadas de I3 e I4 de novembro de I888, Nietzsche também volta a se referir ao "primeiro livro da transvaloração". Entretanto, embora desde o início de setembro ele mantivesse seu projeto inicial de escrever os outros livros do projeto, ocorre uma súbita mudança de planos em 20 de novembro. ${ }^{65}$ Em carta ao estimado interlocutor intelectual que tornava público sua filosofia na Dinamarca no ano de I888, Georges Brandes, Nietzsche acaba por dizer-lhe que havia concluído Ecce Homo, e que este livro deveria ser compreendido como "[...] o prelúdio da Transvaloração de todos os valores, a obra que se encontra diante de mim concluída". ${ }^{66}$

63 Carta a Heinrich Köselitz de 30 de outubro de I888, кSB 8.462.

64 Carta a Constantin Naumann de 6 de novembro de I888, кSв 8.464.

65 Cf. Marton, I990, p. 25.

66 Carta a Georg Brandes de 20 de novembro de I888, кSB 8.482. 
A decisão de não mais considerar $O$ Anticristo como o "primeiro livro", mas sim como a obra que sintetizaria a tarefa da transvaloração, é também expressa em carta de 26 de novembro enviada a Paul Deussen: "Minha transvaloração de todos os valores, cujo título principal é O Anticristo, está concluída", bem como encontra-se nos esboços de cartas que ele não chega a enviar (para Georges Brandes, no começo de dezembro, e no dia 8 do mesmo mês para Helen Zimmer). Todavia, se a correspondência de Nietzsche lança luz sobre o modo como ele tomou para si a tarefa da transvaloração e também permite que o estudioso acompanhe a mudança de rumo em relação ao modo como ele compreende $O$ Anticristo a partir de 20 de novembro, o fato é que Nietzsche não chegará a alterar o prefácio do Crepúsculo dos Ídolos, lugar onde ele menciona que "o primeiro livro da transvaloração de todos os valores" fora concluído em 30 de setembro. Do mesmo modo, a nosso ver, o capítulo "Por que sou um destino" de Ecce Homo pode ser interpretado tanto sob a ótica de que $O$ Anticristo representaria um primeiro livro da transvaloração quanto que representa sua totalidade.

Diante de tais dúvidas, é importante levar em conta que é também no manuscrito de $O$ Anticristo, conservado em Weimar, que podemos ver as oscilaçôes do filósofo em relação ao modo como compreende o título para esta obra nos momentos finais de sua atividade lúcida. Neste sentido, segundo Colli e Montinari, o manuscrito apresenta "duas páginas de título", dispostas do seguinte modo. A primeira, mais antiga, indica: "O Anticristo. Tentativa de uma crítica do cristianismo.Primeiro livro da transvaloração de todos os valores". Sobre a segunda, lê-se: "O Anticristo. [Transvaloração de todos os valores] ${ }^{67}$. Maldição contra o cristianismo". O subtítulo "transvaloração de todos os valores" [...] foi finalmente riscado por Nietzsche. Assim, o último título adotado para esta obra seria: "O Anticristo. Maldição sobre o cristianismo". ${ }^{68}$

Embora restem dúvidas, portanto, se o motivo que leva Nietzsche a abandonar o projeto da transvaloração em quatro livros é de caráter lógico ou decorre de sua oscilação psíquica (que se torna visível para ele mesmo na segunda quinzena de novembro de 1888$)^{69}$, o fato é que desde o início de setembro ele tomara para si a tarefa da transvaloração — e justamente em Sils-Maria: lugar onde sete anos antes tivera o pensamento "mais afirmativo que se pode em

67 O colchete aqui indica que este subtítulo está por debaixo do risco que Nietzsche faria sobre ele.

68 Cf. Colli e Montinari em: Nietzsche, L'Antéchrist, 1974, p. 24I.

69 "Faço tantas bufonarias comigo mesmo e me ocorrem tantas palhaças no espírito, que em plena rua sorrio ironicamente durante uma meia-hora, e não tenho outra expressão. Recentemente tive a ideia de apresentar Malwida sob a aparência de Kundry, aquela que ri, num lugar decisivo de Ecce Homo... Durante quatro dias seguidos fui incapaz de tomar um ar sério" (Carta a Henrich Koselitz de 25 novembro de I888 KsB 8.489). 
absoluto alcançar". Julgando a si mesmo desde o final do ano anterior como alguém que possuía "uma tarefa, um destino, que o nomeiam como queiram", faz sentido que Nietzsche, na medida em que assume a tarefa da transvaloração, nomeie o capítulo final de Ecce Homo com o título "Por que sou um destino". Livro que ademais é concluído com a sentença "Dioniso contra o crucificado", é possível supor que, embora a partir de 20 de novembro de I888 o filósofo tenha abandonado o propósito de redigir os outros dois livros críticos do projeto da transvaloração, o mesmo não chega a ocorrer plenamente em relação ao tema do quarto e último livro: Dioniso. Filosofia do eterno retorno. Afinal, num último esforço, além de concluir o opúsculo Nietzsche contra Wagner, ele também reúne forças para deixar pronto para impressão o manuscrito dos Ditirambos de Dioniso. Isto, porém, é tema para outra ocasião.

\section{Referências}

D'Iorio, P. Le voyage de Nietzsche à Sorrente (Genèse de la philosophie de l'esprit libre). Paris: CNRs Éditions, 20I2; Nietzsche na Itália. A viagem que mudou os rumos da filosofia. Trad. Joana Angélica d'Avila Melo. Rio de Janeiro: Jorge Zahar, 20r4.

GEN (Org.). Dicionário Nietzsche. São Paulo: Ediçōes Loyola, 2016 (Coleção Sendas \& Veredas).

Kaftan, J. "Aus der Werkstatt des Uebermenchen”. In: Deutsche Rundschau 32 (1905), pp. 90-IIO, 237-260.

Marton, S. Nietzsche. Das forças cósmicas aos valores humanos. São Paulo: Brasiliense, 1990.

Nietzsche, F. Sämtliche Werke. Kritische Studienausgabe. Edição organizada por Giorgio Colli e Mazzino Montinari. Berlin/Munique: Walter de Gruyter \& Co., 1967-78. I5 vol.

Nietzsche, F. L'Antéchrist suivi de Ecce Homo. Textes et variantes établis par Giorgio Colli et Mazzino Montinari. Traduit de l'allemand par Jean-Claude Hémery. Paris: Gallimard, 1974.

Nietzsche, F. Sämtliche Briefe. Kritische Studienausgabe em 8 volumes, Berlin/ Munique, Walter de Gruyter \& Co./DTV, 1986.

Nietzsche, F. Obras Incompletas. Col. "Os Pensadores". Seleção de textos de Gerárd Lebrun; tradução e notas de Rubens Rodrigues Torres Filho. Col. "Os Pensadores". $4^{\text {a }}$ ed., São Paulo: Nova cultural, 1987.

Nietzsche, F. Ecce Homo. Como alguém se torna o que é. Tradução, notas e posfácio Paulo César de Souza. São Paulo: Companhia das Letras, I995.

70 Carta a Franz Overbeck de I2 de novembro de I887, кSв 8.I96. 
Rubira, L. Nietzsche: do eterno retorno do mesmo à transvaloração de todos os valores. São Paulo: Discurso Editorial/Editora Barcarolla, 20 Io.

Rubira, L. "Do 'valor' dos 'valores' à fisiologia da arte: pressupostos para a compreensão de O caso Wagner e Nietzsche contra Wagner". In: Revista Dissertatio de Filosofia, v. 38, pp. I34-I49, 2013. 